\title{
A Transmission Congestion Cost Allocation Method in Bilateral Trading Electricity Market
}

\author{
Jiawei Zhao, Jianfeng Lu, Kwok Lun Lo \\ Electronic and Electrical Engineering Department, University of Strathclyde, Glasgow, United Kingdom \\ Email: jiawei.zhao.2013@uni.starth.ac.uk, jianfeng.lu@strath.ac.uk,k.lo@strath.ac.uk
}

How to cite this paper: Zhao, J.W., Lu, J.F. and Lo, K.L. (2017) A Transmission Congestion Cost Allocation Method in Bilateral Trading Electricity Market. Energy and Power Engineering, 9, 240-249. https://doi.org/10.4236/epe.2017.94B029

Received: February 19, 2017

Accepted: March 30, 2017

Published: April 6, 2017

\begin{abstract}
Bilateral trading in electricity is one of the typical deregulated power market trading methods and it has its own way to calculate and allocate congestion cost. In this paper, using as a practical bilateral structure example, the British electricity market is stated in details especially the operation mechanism and the methodology of imbalance settlement. A corresponding congestion cost allocation method for bilateral market is introduced briefly by equations and is simulated in a modified IEEE-14 bus model to investigate its pros and cons.
\end{abstract}

\section{Keywords}

Bilateral Electricity Market, Congestion Management and Congestion Cost Allocation

\section{Introduction}

In 1990, with the trend of electricity entity liberalization, a pool-based wholesale market was designed to bring competition in England \& Wales electricity market [1].On March 2001, the New Electricity Trading Arrangements (NETA) was implemented to substitute the England \& Wales pool with a new concept that market participants are allowed to trade power energy through bilateral transactions [2]. On April 2005, with the inclusion of the Scottish power network, the whole electricity trading in the UK was re-named into the British Electricity Trading and Transmission Arrangements (BETTA) [3]. The British market is based on the bilateral principles which mean any power consumer could purchase electricity from any of the electricity generators who could also sell electricity to any customer. It is requested that transmission capacity usage should be under a non-discriminatory rule [4]. However, transmission congestion acts as quite a challenge to achieve transmission open access. With the integration of Scottish power system, new generation especially wind power has been con- 
nected with the whole network which leads to transmission congestion occurs increasingly [1]. For example, constraint cost was $£ 70$ million in $2007 / 08$, and then in $2008 / 09$ it is raised to $£ 263$ million [1]. Congestion cost allocation became one of the critical issues in congestion management [5]. The section two in this paper briefly introduces the mechanism of the bilateral market in UK. A methodology of bilateral market for congestion cost calculation and allocation is explained in section three. Then in section four, a modified IEEE-14 bus system is utilized to test the above method. A conclusion including the advantages and disadvantages of such congestion cost allocation method is given in the final section.

\section{A Bilateral Market: BETTA}

\subsection{Structure}

Different from the pioneer pool market, the BETTA market achieved that generators and consumers are able to trade electricity power independently through bilateral contracts. Most of the electricity power is traded by Forward/Future contracts and short-term power exchange [6]. The Forward/Future contracts could be drawn up in days, months or even years before actual power delivery [7]. The short-term power exchange is within 24 hours of actual delivery which offers market participants an opportunity to adjust their contract details. Besides being as the asset owner of transmission network, since April 2005, the National Grid Company (NGC) became the system operator (SO) for the whole British power system [1]. As the SO, the NGC needs to keep generation and demand in balance in real time and also maintain system security by balancing mechanism and imbalance settlement. The structure of BETTA is shown in Figure 1 [8].

\subsection{Mechanism}

Although market participants could feel free to trade electrical power in the forward market, they are still required to notify their contractual information in each half hour period, for generator it is the planned generation output and for customer it is the predicted demand, by 11 a.m. one day ahead. This information

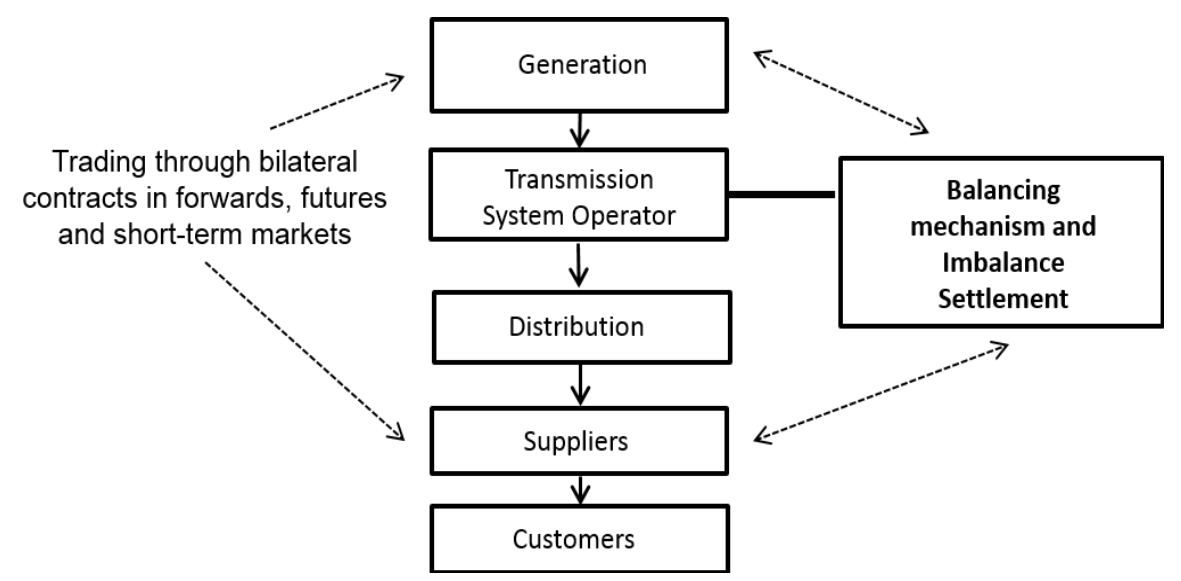

Figure 1. The structure of BETTA. 
is called initial physical notifications (IPNs) which needs to be submitted to the SO [2]. Before the gate closure participants could have chance to modify their IPNs [3]. Once the gate closes, usually one hour before power delivery, the forward market stops which means participants' IPNs turns into the final physical notifications (FPNs) [9]. During the period between gate closure and real time, SO will run the Balancing Mechanism and match the balance between supply and demand so that system security could be guaranteed. Participants have an opportunity to voluntarily submit their offers and bids to let the SO know how much they are willing to pay or charge for the power quantity difference compared with their FPNs [6]. An offer is a participant's price proposal to increase generation or decrease demand and a bid is a participant's price proposal to decrease generation or increase demand. Offers and bids are requested to submit in pairs and one participant is allowed to submit maximum of ten pairs [9]. If transmission constraint occurs, imbalance settlement will be done by the SO mandatorily and that participants whose offers have been accepted will be paid at System Sell Price (SSP) while ones whose bids have been accepted will be charged at System Buy Price (SBP) [8]. SSP and SBP are two imbalance prices which are calculated by the SO based on the collected offers and bids [9]. The initial contracts between each market participant pairs will be honored as usual. Balancing service that NGC provide is consisted of two types of balancing action: energy imbalance actions and system imbalance actions [10]. The transmission constraint management is attached to the system imbalance actions. The SO recovers all the cost of balancing service through a Balancing Service Use of System (BSUoS) charge to all the market participants [10]. BSUoS charge is calculated each half-hour period which divides a whole day into 48 equal intervals, half-hourly. The calculation of transmission congestion cost is included inside the BSUoS charge calculation [11]. The whole process of BETTA mechanism can be presented in Figure 2 [8].

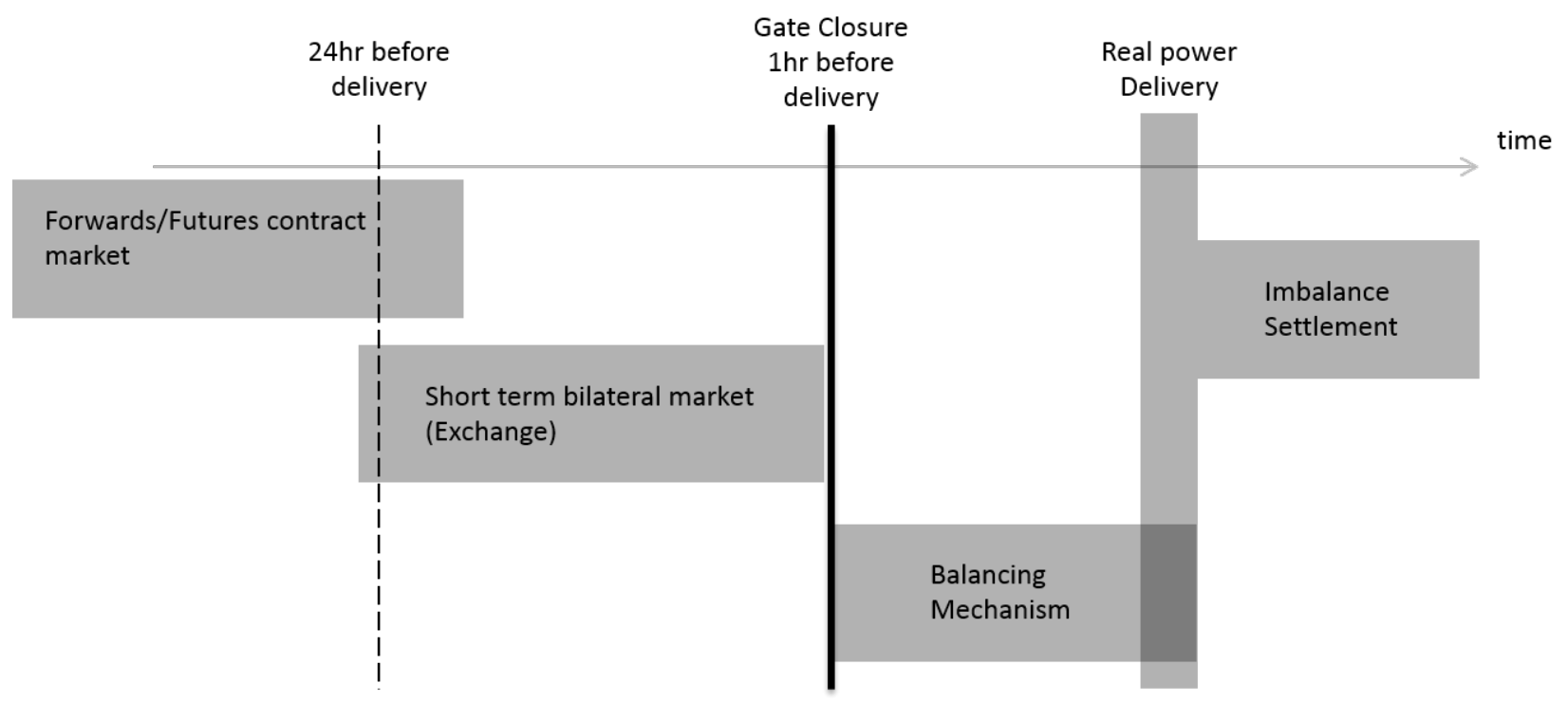

Figure 2. The time frame process of BETTA. 


\section{A Method of Congestion Cost Calculation and Allocation for Bilateral Market}

\subsection{Congestion Cost Calculation}

Reference [12] provides a way to define the congestion cost in bilateral market which is the monetary value difference between the payment to accepted offers and the payment from accepted bids shown in Equation (1).

$$
C_{\text {Congestion }}=\sum P_{\text {acceptedoffer }}-\sum P_{\text {acceptedbid }}
$$

where

$C_{\text {Congestion }}$ : The cost for relieving transmission congestion

$P_{\text {acceptedoffer }}$ : Payment to participant whose offers have been accepted

$P_{\text {acceptedbid }}:$ Payment from participant whose bids have been accepted

\subsection{Congestion Cost Allocation}

In bilateral market, congestion cost details are usually not attached in the bilateral contracts. As a non-profit third party, the SO needs to allocate the congestion cost to all market participants in the network system on pro rata rules [13]. Reference [14] suggests that generators and customers need to shoulder the cost of congestion relief together based on a half-half basis. Each half is proportionally allocated to generator group/customer group by considering their real power export/import. Such congestion cost allocation method is represented through Equations (2)-(4).

$$
\begin{gathered}
C A_{\mathrm{gen}_{i}}=\frac{P_{\mathrm{gen}_{i}}}{\sum_{i=1}^{N_{G}} P_{\mathrm{gen}_{i}}} \times C A_{\mathrm{gen}^{\text {total }}}^{\text {to }} \text { For generators } \\
C A_{\text {load }_{i}}=\frac{P_{\text {load }_{i}}}{\sum_{i=1}^{N_{L}} P_{\text {load }_{i}}} \times C A_{\text {load }}^{\text {total }} \text { For loads } \\
C A_{\text {gen }}^{\text {total }}=C A_{\text {load }^{\text {total }}}^{\text {to }}=\frac{1}{2} \times C A^{\text {total }}
\end{gathered}
$$

where

$C A_{\mathrm{gen}_{i}}$ : The congestion cost allocation of generator $i$

$C A_{\text {load }}$ : The congestion cost allocation of load $i$

$C A_{\text {gen }}^{\text {total }}$ : The total congestion cost of generators

$C A^{\text {total }}$ : The total congestion cost of loads

$C A^{\text {total }}$ : The total cost of congestion relief

$P_{\mathrm{gen}_{i}}:$ The real powerdispatch generation of generator $i$

$P_{\text {load }_{i}}$ : The real power dispatch consumption of load $i$

$N_{G} \& N_{L}$ : The total number of generators and loads respectively

\section{Case Study}

\subsection{Data and Results}

Amodified IEEE-14 bus model has been built using the software package Mat- 
power for simulating and testing the congestion cost calculation and allocationmethod in section 3. The system model is shown in Figure 3.

This case study consists of three scenarios. Scenario 1 simulates the situation that the transmission capacity on branch 4 - 7 suddenly drops which cause congestion on line $4-7$. Scenario 2 simulates the situation that load 4 on bus 4 increases which lead to a congestion on branch $4-5$. Scenario 3 simulates load 4 on bus 4 and load 9 on bus 9 increase which result in two branch congestion on branch 3 - 4 and branch $4-5$ respectively. The congested branches in three scenarios are shown in Table 1 . The variation of generation/demand and the offer \& bid pairs of each participant is shown in Table 2. The congestion cost in each scenario is shown in Table 3. Congestion cost allocation of each participant in each scenario is shown in Figures 4-6.

\subsection{Discussion}

After the simulation, it is found that the above congestion cost allocation scheme is following a proportional rule that the participant who generates or consumes more power will be portioned more congestion cost. It looks like an equitable approach to constraint cost recovery. However, after analysing the power flow direction in each scenario, it is indicated that some of the participants have no chance to utilize the congested line which means they have no contribution to the transmission congestion. Power flow analysis of each scenario is shown in

\section{Figures 7-9.}

The red line with a cross stands for a congested line. The green line indicates the power flow does not exceed the line limit. Although the blue line represents an uncongested line as well, going along with the blue direction, the power output from a generator could go through the congested line and the power received by a load could come from the congested line which means participants

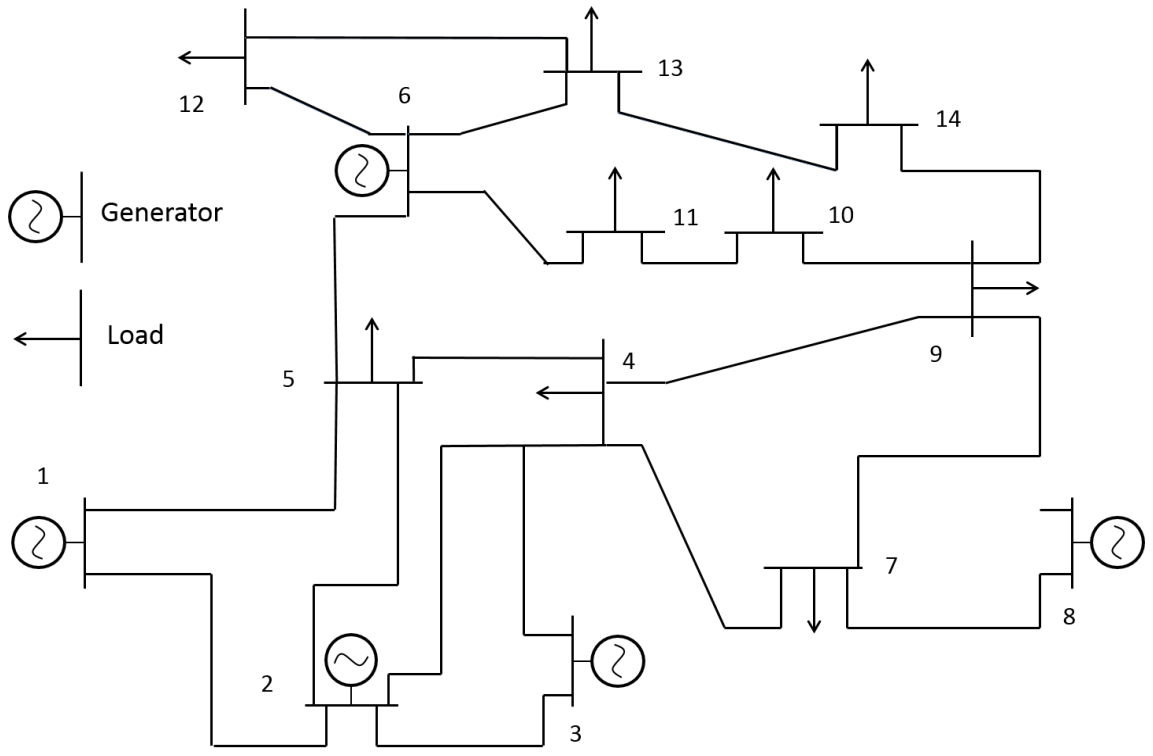

Figure 3. The IEEE-14 bus system. 


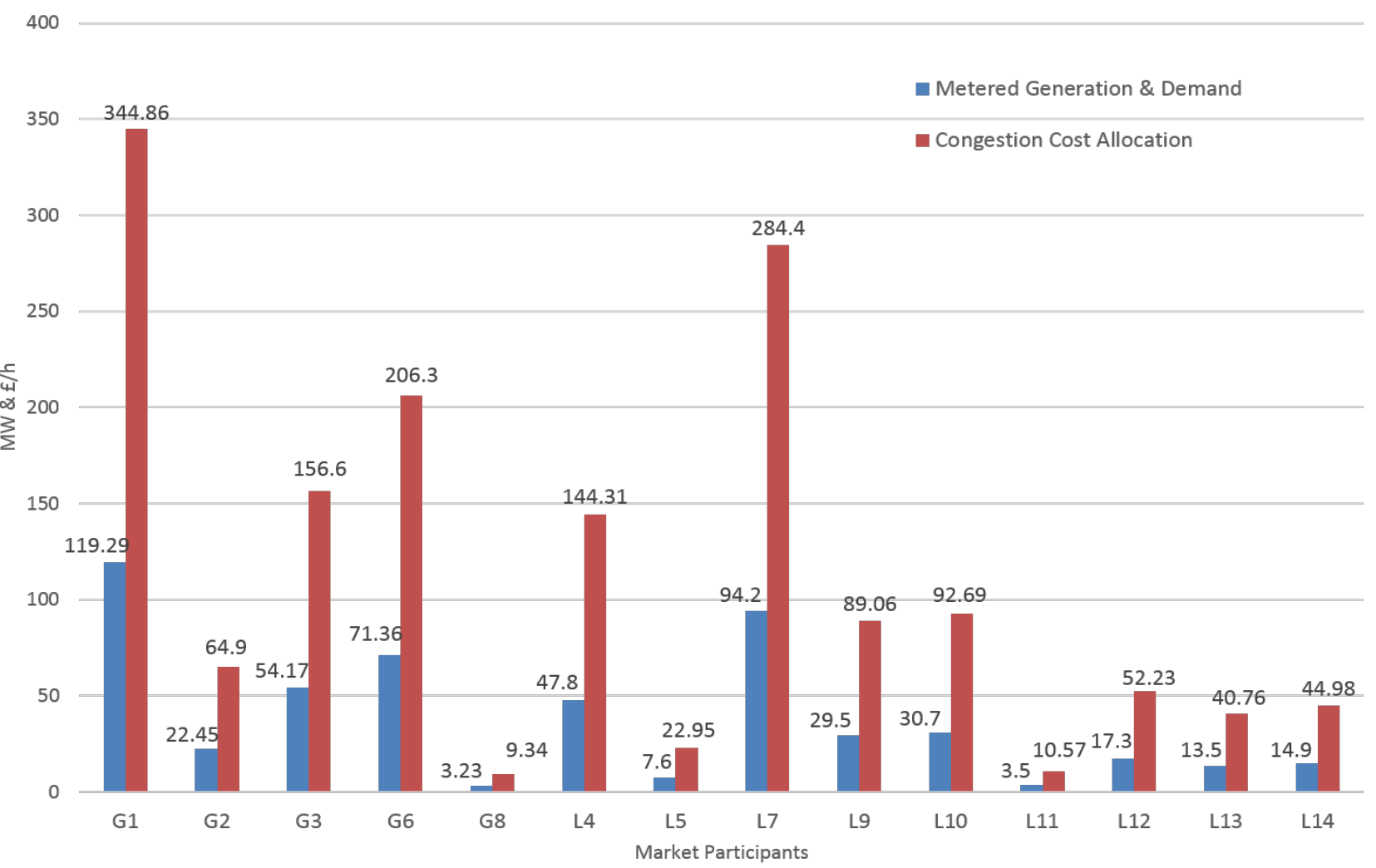

Figure 4. Congestion cost allocation of each market participant in scenario 1.

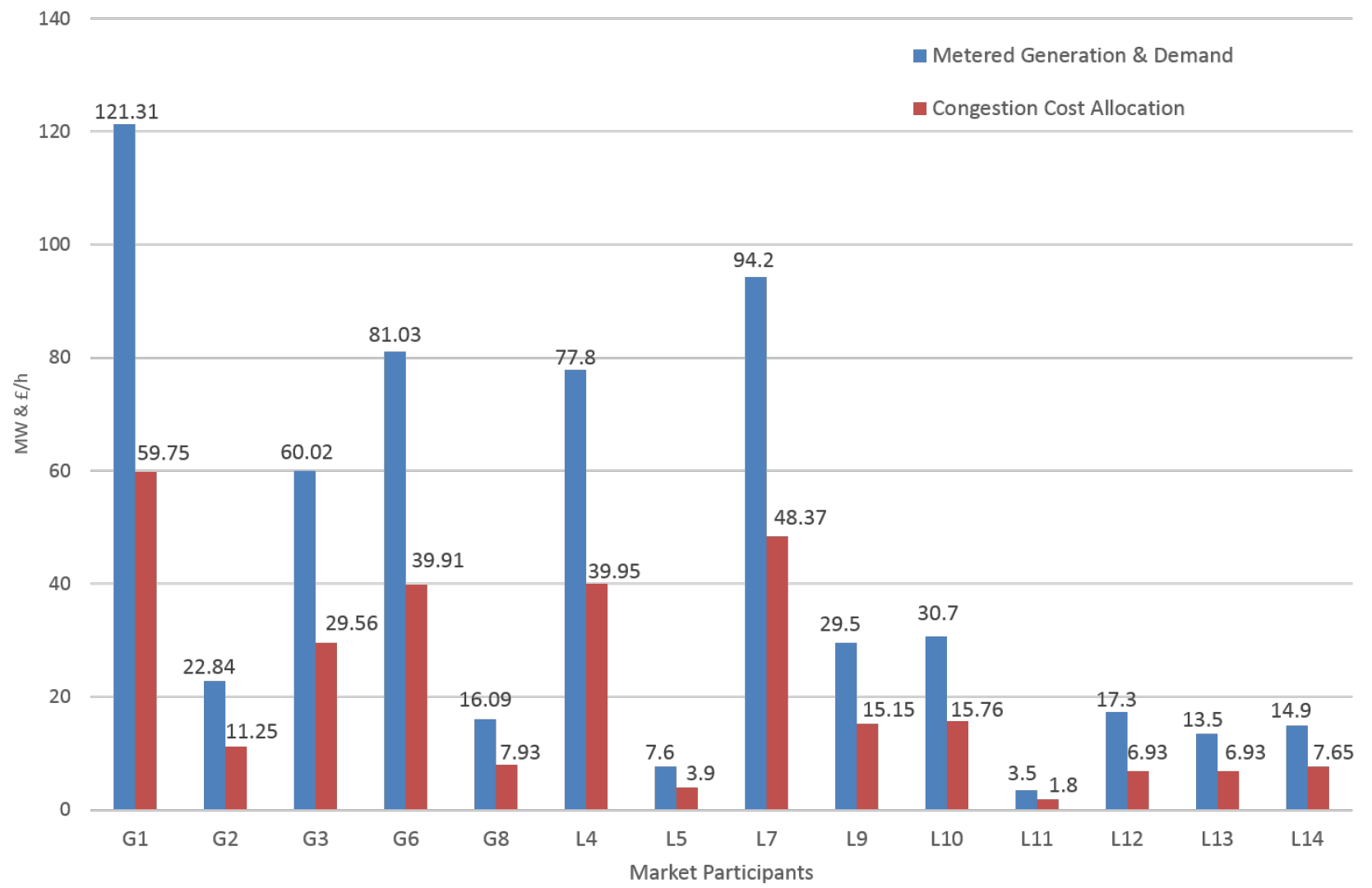

Figure 5. Congestion cost allocation of each market participant in scenario 2. 


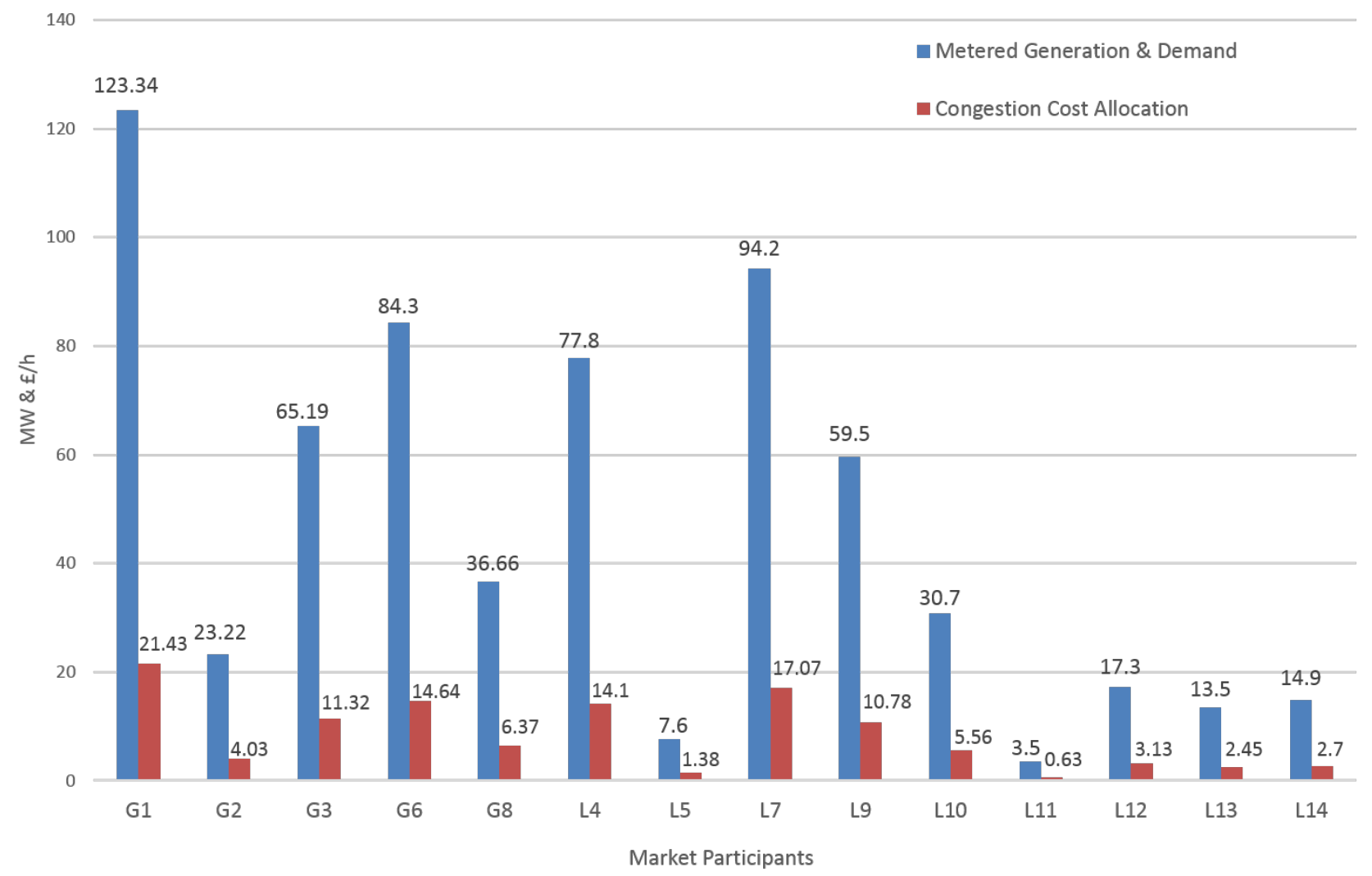

Figure 6. Congestion cost allocation of each market participant in scenario 3.

Table 1. Congested branches in three scenarios.

\begin{tabular}{cccc}
\hline Scenario & Congested branches & $\begin{array}{c}\text { Transmission volume } \\
(\mathrm{MW})\end{array}$ & $\begin{array}{c}\text { transmission limit } \\
(\mathrm{MW})\end{array}$ \\
\hline 1 & $4-7$ & 82.33 & 60 \\
2 & $4-5$ & 65.36 & 60 \\
3 & $3-4$ & 62.12 & 60 \\
& $4-5$ & 64.90 & 60 \\
\hline
\end{tabular}

Table 2. Variation of generaion/demand and offer \& bid pairs of each participant.

\begin{tabular}{cccccc}
\hline Participants & $\begin{array}{c}\text { Volume } \\
\text { variation in } \\
\text { scenario } 1 \\
(\mathrm{MW})\end{array}$ & $\begin{array}{c}\text { Volume } \\
\text { variation in } \\
\text { scenario } 2 \\
(\mathrm{MW})\end{array}$ & $\begin{array}{c}\text { Volume } \\
\text { variation in } \\
\text { scenario 3 } \\
(\mathrm{MW})\end{array}$ & $\begin{array}{c}\text { Offer } \\
(\mathfrak{E} / \mathrm{MWh})\end{array}$ & $\begin{array}{c}\text { Bid } \\
(\mathfrak{E} / \mathrm{MWh})\end{array}$ \\
\hline G1 & -8.66 & -3.62 & -3.78 & 40 & 10 \\
G2 & -1.7 & -0.39 & -0.25 & 40 & 10 \\
G3 & -25.96 & 1.1 & -4.51 & 45 & 10 \\
G6 & -6.99 & -12.66 & -11.55 & 45 & 10 \\
G8 & 34.94 & 14.28 & 18.33 & 50 & 10 \\
L4 & - & 30 & 30 & 30 & 10 \\
L9 & - & - & 30 & 30 & 10 \\
\hline
\end{tabular}


Table 3. Congestion cost of each scenario.

\begin{tabular}{cccc}
\hline Scenario & $\begin{array}{c}\text { Congestion cost for gen } \\
(\mathfrak{E} / \mathrm{h})\end{array}$ & $\begin{array}{c}\text { Congestion cost for load } \\
(\mathfrak{E} / \mathrm{h})\end{array}$ & $\begin{array}{c}\text { Total congestion cost } \\
(\mathfrak{E} / \mathrm{h})\end{array}$ \\
\hline 1 & 781.95 & 781.95 & 1563.9 \\
2 & 148.4 & 148.4 & 296.8 \\
3 & 57.8 & 57.8 & 115.6 \\
\hline
\end{tabular}

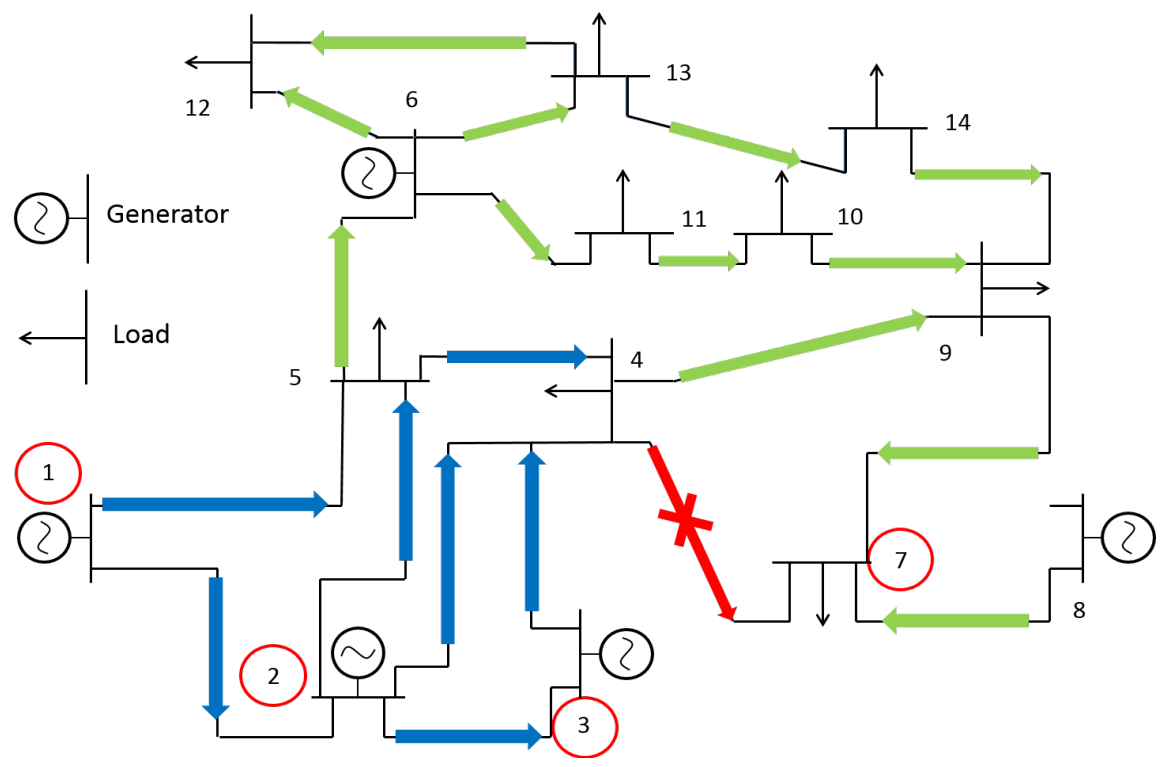

Figure 7. Power flow direction analysis of scenario 1.

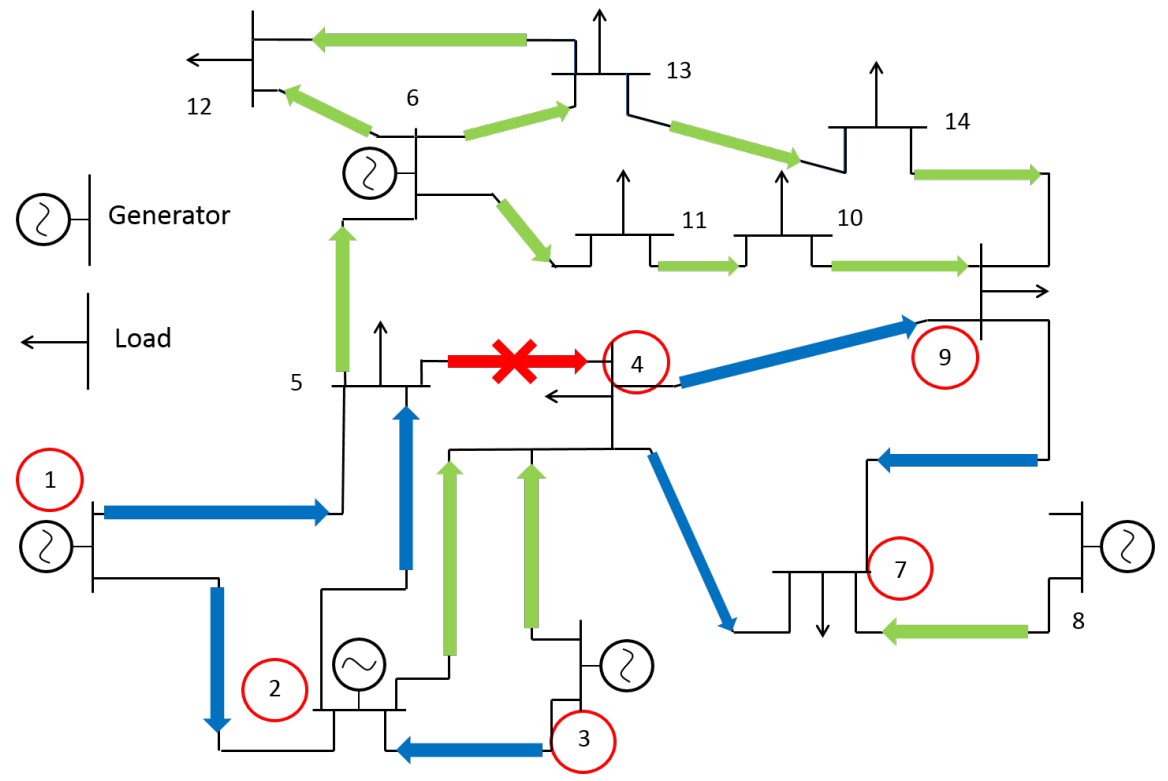

Figure 8. Power flow direction analysis of scenario 2.

who have an opportunity to use a blue line will stand a chance of using a congested branch. Such participant suspects are labeled by a red circle in each scenario figure. According to the flow directions, the rest of participants without a 


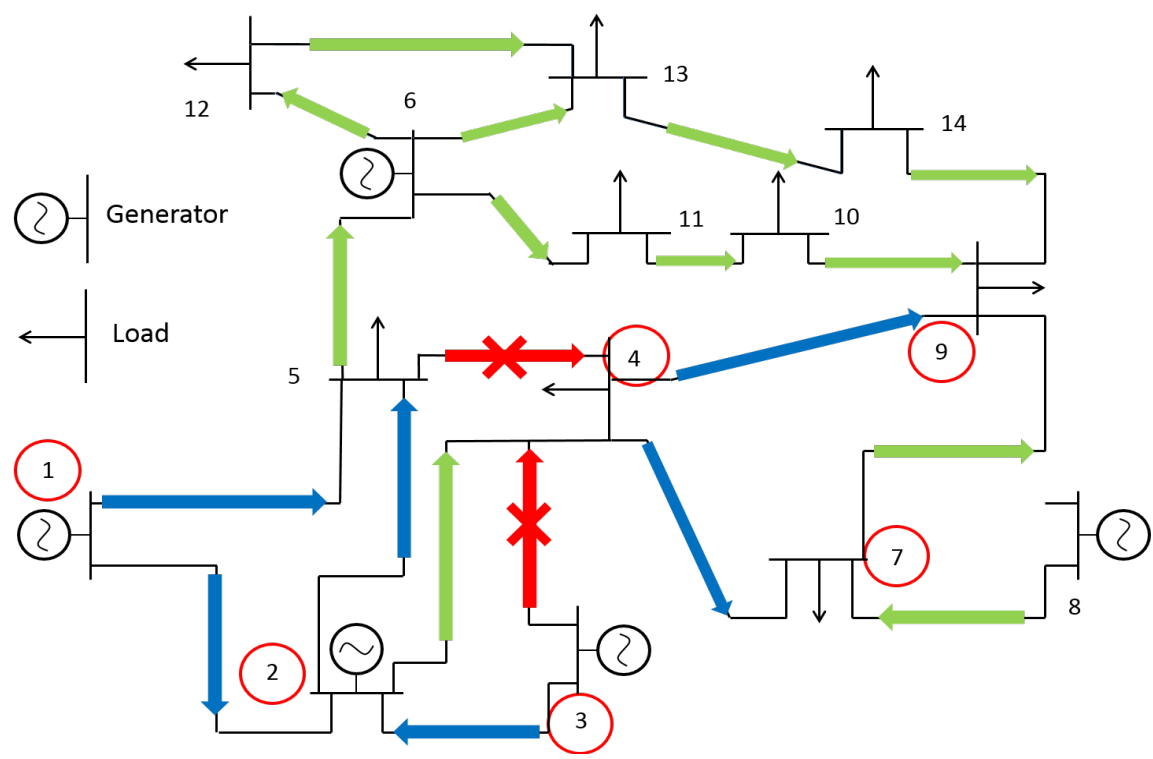

Figure 9. Power flow direction analysis of scenario 3.

red circle have no chance to utilize the congested line but they still need to shoulder the congestion cost by adopting the mentioned allocation method.

\section{Conclusion}

Under bilateral structure, more competition has been brought in the electricity market which can be indicated by electricity price reduction, market liquidity enhancement and price information growth. The congestion cost allocation method in this paper is simple and straightforward. The drawback is the above method does not consider participants' contribution to the transmission congestion. It may be considered unreasonable and unfair for the participants who have no contribution to the congestion to shoulder the congestion cost of the whole power network system.

\section{References}

[1] Newbery, D.(2011) High Level Principles for Guiding GB Transmission Charging and Some of the Practical Problems of Transition to an Enduring Regime.Paper for Ofgem, Energy Policy Research Group, University of Cambridge.

[2] Simmonds,G. (2002) Regulation of the UK Electricity Industry. CRI Industry Brief, University of Bath. (Desktop published by Jan Marchant 2002 Edition)

[3] Perekhodtsev, Dmitri, and Guido Cervigni. (2010) UK Transmission Congestion Problem: Causes and Solutions.SSRN Scholarly Paper. Rochester, NY: Social Science Research Network.

[4] Singh, H., Hao,S. and Papalexopoulos,A. (1998) Transmission Congestion Management in Competitive Electricity Markets.IEEE Transactions on Power Systems,13, 72-80.https://doi.org/10.1109/59.667399

[5] Baran, M. E., V. Banunarayanan, and K. E. Garren. (2000) Equitable Allocation of Congestion Relief Cost to Transactions.IEEE Transactions on Power Systems,15, 79-85.https://doi.org/10.1109/59.867144

[6] Hesmondhalgh,S.(2003) Is NETA the Blueprint for Wholesale Electricity Trading 
Arrangements of the Future.Power Systems, IEEE Transactions,18,548-554. https://doi.org/10.1109/TPWRS.2003.810699

[7] Lo, K.L. and Yuen, Y.S. (2002) Deregulation of Electric Utilities.Power System Restructuring and Deregulation, Wiley, 50-74.

[8] Sun,J.(2014) Demand Side Approaches for Congestion Management in Electricity Market. Ph.D. dissertation, Dept. EEE. Eng., Univ. Strathclyde.

[9] ELEXON. (2016, Accessed on 24 October 2016). Imbalance Pricing Guidance. https://www.elexon.co.uk/wp-content/uploads/2016/10/Imbalance_Pricing_guidanc e_v11.0.pdf

[10] National Audit Office. (2014, Accessed on May 2014). Electricity Balancing Service. https://www.nao.org.uk/wp-content/uploads/2014/05/Electricity-Balancing-Services .pdf

[11] National Grid. (2017, Accessed on 17 Jan 2017). November 2016 Monthly Balancing Service Summary 2016/2017.

http://www2.nationalgrid.com/UK/Industry-information/Electricity-transmission-o perational-data/Report-explorer/Services-Reports/

[12] Li, J., Gu, C., Bhakar, R.and Li.F. (2016) Transmission Use of System Charging for Differentiating Long-Term Impacts from Various Generation Technologies. CSEE Journal of Power and Energy Systems,2, 11-19. https://doi.org/10.17775/CSEEJPES.2016.00017

[13] Abdullah, M. P., Hassan,M. Y. and Hussin,F. (2010) Assessment of Contribution-Based Congestion Cost Allocation Using AC and DC for Bilateral Market.2010 IEEE International Conference on Power and Energy, 897-901. https://doi.org/10.1109/PECON.2010.5697706

[14] Abdullah,M.P.(2008) Congestion Management and Security Cost Allocation in Electricity Market," Ph.D. Dissertation, Dept. EEE. Eng., Univ. Strathclyde.

Submit or recommend next manuscript to SCIRP and we will provide best service for you:

Accepting pre-submission inquiries through Email, Facebook, LinkedIn, Twitter, etc. A wide selection of journals (inclusive of 9 subjects, more than 200 journals)

Providing 24-hour high-quality service

User-friendly online submission system

Fair and swift peer-review system

Efficient typesetting and proofreading procedure

Display of the result of downloads and visits, as well as the number of cited articles

Maximum dissemination of your research work

Submit your manuscript at: http://papersubmission.scirp.org/

Or contact epe@scirp.org 